\title{
Geological interpretation of the cosmic materials from the South of Western Siberia in connection with the petroleum potential of the sedimentary cover
}

\author{
Andrew Belonosov ${ }^{1,2}$, Anton Kudryavtsev ${ }^{2}$, Sergey Sheshukov ${ }^{2}$, and Dmitry Borisov ${ }^{3}$ \\ ${ }^{1}$ Tyumen Industrial University, 625000, Tyumen region, Tyumen, Russia \\ ${ }^{2}$ West Siberian branch of the Trofimuk Institute of Petroleum Geology and Geophysics of Siberian \\ Branch Russian Academy of Sciences (WSB INGG SB RAS), laboratory " Geology of oil and gas», \\ 625026, Tyumen region, Tyumen, Russia \\ ${ }^{3}$ V.I.Shpilman research and analytical centre for the rational use of the subsoil, 625026, Tyumen \\ region, Tyumen, Russia
}

\begin{abstract}
In the South of Western Siberia oil-perspectivity Jurassic deposits are characterized by multi - and small-scale. The interpretation of earth remote sensing materials in the visible, near and far infrared ranges allowed to evaluate the oil potential of numerous domes and depressions on the basis of combining geodynamically stressed zones and calculating the physical characteristics of the earth's surface (albedo, radiation coefficient, thermal inertia, convective heat flow, daily evaporation of moisture, DEM, weather conditions, etc.), including the procedure of reference classification, where the standards are the nearest oil and gas condensate fields. The forecast boundary of "oil and gas condensate" lands of the South of Western Siberia is displaced to the latitude of u.v. Lebyazhye of the Eastern part of the Kurgan region.
\end{abstract}

\section{Introduction}

The geography of oil and gas searches is expanding every year. Despite the fact that the main vector of prospecting geological and geophysical research is directed to the northern and eastern outskirts of Western Siberia, the western and southern parts still belong to reserve resource territories [1]. With the accumulation of new materials of geological and geophysical work, a regional reassessment of the oil potential of poorly studied large structural and tectonic elements is periodically carried out: anteclise, syneclise, anticlines, depressions, domes and hollows [2-3].

In the south of Western Siberia, including Tyumen (without autonomous okrugs Khanty-Mansi Autonomous Okrug and Yamalo-Nenets Autonomous Okrug), Kurgan and, partially, Omsk and Sverdlovsk regions, according to the results of regional and fragmented areal seismic surveys, taking into account about 300 exploration wells already drilled, a reduction in sedimentary cover southward. In the border zone with the Republic of Kazakhstan, its thickness is on average 50-100 meters.

Currently, the border of oil-prospective lands in the south of Western Siberia is conditionally drawn along the administrative border of the Uvat and Vagai districts of the Tyumen region.

\section{Relevance}

On the other hand, the pre-Jurassic base (conventionally Triassic-Paleozoic basement) of the West Siberian Plate (WSP) has a stepped structure and plunges to the north, and oilprospective Jurassic sedimentary cover deposits are characterized by multi-dome and small dome [3-5]. Given the small size of the structures, and, accordingly, the small reserves of 
hydrocarbon raw materials, the question arises of how to classify them into productive and "empty" ones, since it is not possible to verify each small anticline structure with a deep (about $3 \mathrm{~km}$ ) exploratory well. Therefore, leading oil companies are reluctant to consider the oil prospects of the southern regions of Western Siberia, and medium and small companies, as a rule, do not have enough financial support for the full cycle of exploration. From here, the following problems become relevant:

1) to offer and interest leading oil and gas companies with large prospective geological objects;

2) apply the methodology for remote forecasting of "oil" lands, after conducting oil prospective zoning and filtering of "empty" and productive structures.

\section{Problem state}

The materials of regional seismic studies taking into account borehole materials show that several large depressions are identified in the sedimentary cover in the south of the WSP, which correspond to submeridional graben-like extended structures of the pre-Jurassic basement [6-8].

On the one hand, graben-like depressions are characterized by a complete set of Mesozoic sedimentary deposits from the Triassic to Cretaceous. On the other hand, grabenlike basement structures are limited by deep faults, which are translators of hydrocarbon fluids to the earth's surface [9]. Thirdly, debris demolition material is accumulated in the depressions, which is usually a good collector. Fourth, the presence of the Bazhenov horizon is a high-quality cover, which sharply increases the likelihood of the formation of oil deposits [2].

Due to the insufficiency of geological and geophysical materials, various packages of Earth remote sensing (ERS) materials find their place in the detailed regional oil exploration work.

To decrypt these packets, not only «classical» pattern recognition can be used, but also advanced software products using neural networks.

Satellite technologies make it possible to assess, to a first approximation, the oil potential of depressions for setting up further onshore exploration work [3-5, 10-12].

\section{Problem solving methods}

To solve the above problems, space materials were used in the visible, near and far infrared ranges [10-12]. These are fragments of space images at a scale of 1: 500000 (a component of the Geolart-1000 remote base, a composite based on satellite imagery materials from KATE-200 cameras - spectral zones 510-850 nm), fragments of a global mosaic taken by an ETM + scanner of «Landsat-7» satellite in the spectral range of 0.53-0.9 and 1.55-1.75 microns, as well as a digital elevation model (DEM) - SRTM DEM based on data from the SIR-C and X-SAR sensors of the Shuttle spacecraft.

The methodology of geological analysis and decoding of space materials consisted of three stages [3-4].

The first stage - «Processing and decoding of space images» - involved topographic and geodetic linking of space images, geomorphological studies and lineament analysis. Further, when generalization of the lineament pattern, geodynamically stressed zones (GDNZ) were identified. They represent a «framework of mobile tensile structures» and characterize regional deep fracturing, as well as fluid dynamic processes in the sedimentary cover.

The second stage - «Integration of geological and geophysical materials with GDNZ systems» - consisted in a comparative analysis of the GDNZ framework with geophysical and geochemical fields, with structural maps, with geological sections, data from exploration wells, etc. etc. 
The third stage - «Geological interpretation of space materials» - consisted of examining the processes of oil and gas accumulation in the traps of hydrocarbons in the framework of the GDNZ.

An interesting fact is that hydrocarbon traps with proven oil and gas potential are within a certain radius from the intersection of the GDNZ (nodes GDNZ). On the day surface, the nodes of GDNZ are characterized by anomalous positive or negative effects of geophysical, geochemical, thermal, radioactive, microbiological and other fields.

Large depressions of the sedimentary cover that inherit the general structure of a series of grabens of the foundation, as a rule, coincide in plan with the GDNZ highlighted from space materials.

An analysis of the regional distribution of hydrocarbon deposits on remote sensing materials showed that most oil and gas fields are located near linear thermal zones. These zones, as a rule, display active fluid-conducting transit faults, leaving the foundation and cutting the entire sedimentary cover to the earth's surface. On maps of a larger scale, oil and gas deposits are confined to local thermal anomalies, or to their «rings». This is confirmed by the verification of the ground geothermal and geochemical surveys. The explanation of this fact is the vertical process of heat and mass transfer by the fluid-conducting systems of cracks and faults, delineating hydrocarbon traps [9].

Thus, thermal space survey (TSS) can serve as the first step in determining the oil and gas potential of structural and tectonic elements of the upper part of the sedimentary cover in poorly studied territories.

But it should be noted that not all thermal anomalies are a direct criterion for oil and gas saturation of sedimentary deposits.

In order to systematize space thermal anomalies (which of them are associated with hydrocarbon deposits, and which are not), a methodology was developed at the Center for Environmental Safety of the Russian Academy of Sciences of the Russian Federation (St. Petersburg) based on the use of multiple TSS and a special algorithm for processing thermal images of the earth's surface (ES). The methodology included the calculation of the physical characteristics of the earth's surface, such as the total solar radiation flux density, albedo, emissivity, thermal inertia (TI) ES, convective heat flux (CHF) from the subsoil, daily moisture evaporation (DM) ES, soil moisture, digital relief model (DEM) ES, soil structure, meteorological conditions, the concentration of optically active gases (CO2, SO2) in the atmosphere and time $[10,12]$.

The calculation algorithm for CHF, TI and DM was based on a mathematical model of the daily course of the Earth's surface temperature (EST), taking into account weather data (temperature, pressure, air humidity, wind speed, cloud cover) and the main factors under the influence of which the EST is formed.

For zoning of the territory of the South of Western Siberia, digital mosaics were prepared using the Geomatics and ERDAS software tools based on the quantitative characteristics of the earth's surface.

The interpretation of space materials with the aim of forecasting oil potential lands was carried out through the classification procedure of the data obtained above. For the reference classification, the maximum likelihood method was applied [10].

As a training sample, oil, oil condensate and gas condensate fields used in the GIS "Natural Resources of Russia" were used. For analysis, several standards were selected, representing a set of features of the ES in already known oil and gas fields located in the vicinity of the studied territory.

\section{The discussion of the results}

As a result, from the selected standards (deposits) in the South of Western Siberia right up to the border with the Republic of Kazakhstan, spatially recorded places (areas) where 
indications from the Kalchinsky, Polunyakhsky, Taytymsky and Tevrizsky oil, oil and gas and gas condensate fields appeared.

The spatial distribution of these places has a clear pattern. Starting from the latitude of Tobolsk and to the state border with the Republic of Kazakhstan, the number and area of these promising places is gradually reduced, and in the border areas it is completely disappearing. This trend is logical, since the thickness of the sedimentary cover, for which the standards (deposits) were chosen, is practically reduced towards the border with the Republic of Kazakhstan.

When applying a structural map along the roof of the Bazhenov horizon with oil potential areas identified using the reference classification according to remote sensing data, approximately half of the small structures were classified as unpromising. Thus, the number of promising anticlinal structures underwent the first stage of filtration and their number sharply decreased, almost 2 times.

\section{Conclusion}

According to the remote forecast of hydrocarbon deposits carried out using Earth remote sensing materials, the border of oil potential in the South of Western Siberia has shifted to the latitude of the urban area Lebyazhye of the Kurgan region.

The analysis of the spatial distribution of areas (grounds) with signs of the Kalchinsky, Polunyakhsky, Taytimsky and Tevrizsky oil and gas and gas condensate fields, identified by remote sensing data, and Graben-shaped hollows identified by regional seismic work, showed: a) potential grounds are mainly located within hollows; b) potential areas gravitate to the side parts of the hollows; c) the greatest number of grounds is fixed on the eastern boards of hollows.

The materials of geological-geochemical and geophysical studies do not exclude the possibility of the presence of hydrocarbon deposits in the Paleozoic floor of the southern regions of Western Siberia. But in this case, when attracting remote sensing data, other signs of the ES will be taken into account, and, accordingly, another zoning of the territory, another classification and other standards. These procedures will already be aimed at finding hydrocarbon deposits in the foundation.

The results of these studies can significantly optimize oil exploration.

\section{References}

1. I.V. Shpurov, J.E. Faibusovich, V.A. Ryl'kov, Science and Energy, 1, 10-16 (2011)

2. Y.A. Tsymbalyuk, F.Y. Borkun, Y.A. Shepelev, in the collection: NEFTGAZTEK Materials of the VI Tyumen International Innovation Forum. Government of the Tyumen region, committee on innovations of the Tyumen region, 438-449 (2015)

3. A.R. Kurchikov, A.Y. Belonosov, O.S. Martynov, Материалы VII научнопрактической конференции «Ways of the Western Siberia's oil and gas potential realization of Khanty-Mansiysk Autonomous Okrug», 1, 41-44 (Khanty-Mansiysk city, 2003)

4. A.Y. Belonosov, R.I. Timshanov, A.E. Kudryavtsev, S.A. Sheshukov, Academic Journal of Western Siberia, 12, 3(64), 5-6 (publishing house "Vector-Buk", Tyumen, 2016)

5. A.Y. Belonosov, D.V. Borisov, A.E. Kudryavtsev, S.A. Sheshukov, Interexpo GEOSiberia-2017. XIII International Scientific Congress «Subsoil Use. Mining engineering. Directions and technologies for the search, exploration and development of mineral deposits. Geoecology», 2, 172 - 175 (Novosibirsk, SSUGT, 2017)

6. V.N. Voronov, Y.A. Tsymbalyuk, L.V. Smirnov, Science and Energy, 6, 43-50 (2011)

7. N.P. Kirda, Geology and Mineral Resources of Siberia, 3, 39-49 (2013)

8. N.P. Kirda, Mountain journal, 10 (113), 20-39 (2013) 
9. V.M. Matusevich, A.R. Kurchikov A.V. Rylkov, News of higher education institutions. Oil and gas, 2, 4-13 (2011)

10. V.I. Gorny, S.G. Kritsuk, Second international conference «Prospects for development and opening of fuel and energy base of the North-West economic region of the Russian Federation», Thesis of reports, 41-42, (2000)

11. A.Y. Belonosov, A.E. Kudryavtsev, D.V. Borisov, Journal of Siberian Federal University. Engineering \& Technologies, 10(6), 758 - 763 (2017)

12. V.I. Gorny, I.V. Stepanov, Exploration and protection of subsoil, 9, 39-43 (2001) 